\title{
COVID-19 Pandemi Döneminde Elit Sporcuların Uyku Kalitesi ile Beslenme Durumunun Değerlendirilmesi
}

\author{
DOI: 10.26466/opus.909434
}

$*$

\begin{abstract}
Aysun Yüksel *
* Dr. Öğr. Üyesi, Sağlık Bilimleri Üniversitesi, Beslenme ve Diyetetik Bölümü, İstanbul/Türkiye E-Posta: dyt.aysun@hotmail.com

ORCID: $\underline{0000-0002-6580-0207}$

\section{Öz}

COVID-19 pandemisi spor sektörünü derinden etkilemiştir. Sporcuların evde kalma zorunluluğu, spor salonlarına veya tümüyle antrenmana/antrenöre erişimlerinin kısıtlanması, iptal edilen organizasyonlar, belirsizlik vb. birçok faktör stres ve kaygı düzeyini artırırken, uyku ve beslenme alışkanlıklarında değişime neden olmuştur. Bu çalışmada, elit sporcularm uyku, stres, anksiyete ve depresyon durumlarını belirlemek, beslenme durumları ile vücut kompozisyonları arasındaki ilişkiyi değerlendirmek amaçlanmıştır. Çalışma 13 profesyonel kadın voleybol takımı oyuncusu ile yapılmışıı. Tüm sporcular ile yüz yüze görüşülerek genel özellikleri, uyku kalitesi, stres-anksiyete-depresyon düzeyleri ve yeme davranışları ölçekler aracılıyla belirlenmiştir. Ayrıca sporcularm 24-saatlik geriye dönük besin tüketimleri sorgulanmış, vücut kompozisyonu analizleri yapılmıştır. Sporcuların ortalama boy uzunlukları 173,62 $\pm 7,69 \mathrm{~cm}$, vücut yağ yüzdeleri $22,46 \pm 3,69^{\prime}$ dur. Sporcularn çoğunluğunun $(\% 53,85)$ kötü uyku kalitesine sahip olduğu belirlenmiştir. Kötü ve iyi uyku kalitesine sahip olanları toplam vücut sivı miktarn $(\mathrm{kg})$ ortalamaları arasındaki fark anlamlı bulunmuştur. Stres, anksiyete ve depresyon düzeyleri normalin üzerinde olanların oranı sırasıyla \%38,5, \%38,5 ve \%46,2'dir. Çalışmada uyku puanının yağsız kütle $(r=-, 565 p=0,044)$, kas kütlesi $(r=-, 584 p=0,036)$ ve protein miktarı $(r=-, 566 p=0,044)$ ile negatif yönlü ilişkisi belirlenmiştir $(p<0.05)$. Günlük alınan enerjinin maksimum değerinin 1781,75 kkal, ortalama protein miktarının $0,81 \pm 0,22 \mathrm{~g} / \mathrm{kg}$ olduğu saptanmıştır. Sporcular için pandeminin olumsuz etkilerine yönelik önlemler alınmalıdır. Aynı zamanda COVID-19'a yakalanan sporcuların sağhlkları ve spor performansları yakından takip edilmelidir.
\end{abstract}

Anahtar Kelimeler: COVID-19, spor, beslenme, uyku kalitesi, vücut kompozisyonu 


\title{
Evaluation of the Sleep Quality and Nutrition Status of Elite Athletes in the COVID-19 Pandemic
}

\begin{abstract}
The COVID-19 pandemic has deeply affected the sports industry. The obligation of athletes to stay at home, restricting access to gyms or completely training/trainer, canceled organizations, uncertainty, etc. while these factors increased stress and anxiety levels, they also changed sleep and eating habits. The study was conducted with 13 professional women's volleyball team players.

Face-to-face interviews were conducted with all athletes, and scales were used to assess their general characteristics, sleep quality, stress-anxiety-depression levels, and eating habits. In addition, the athletes' 24-hour retrospective food consumption was questioned, and body composition analyses were performed. The athletes' average height is $173.62 \pm 7.69 \mathrm{~cm}$, and their body fat percentage is $22.46 \pm 3.69$ percent. Most of the athletes (53.85\%) were found to have poor sleep quality. The difference between the mean total body fluid amount $(\mathrm{kg})$ of those with poor and good sleep quality was found to be significant. The percentage of those who have stress, anxiety, and depression scores above normal is $38.5 \%, 38.5 \%$ and $46.2 \%$, respectively. In the study, a negative correlation between sleep score and lean mass ( $r=-$ $0.565 p=0.044)$, muscle mass $(r=-0.584 p=0.036)$ and protein amount $(r=-0,566 p=0.044)$ was determined $(p<0.05)$. It was determined that the maximum daily calorie intake was $1781.75 \mathrm{kcal}$, and the mean protein amount was $0.81 \pm 0.22 \mathrm{~g} / \mathrm{kg}$. Precautions should be taken to avoid the pandemic's negative effects on athletes. At the same time, athletes infected with COVID-19 should have their health and athletic performance closely monitored.
\end{abstract}

Keywords: COVID-19, sport, nutrition, sleep quality, body composition 


\section{Giriş}

Dünya, bir yılı aşkın süredir yeni tip bir korona virüsün (SARS-CoV-2) neden olduğu, büyük bir salgınla mücadele etmektedir. Aralık 2019 yılında ilk kez rapor edilen bu virüsün neden olduğu COVID-19 hastalığı, kısa zamanda tüm dünyaya yayılmış ve 11 Mart 2020 tarihinde pandemi ilan edilmiştir (WHO, 2020). Türkiye'de de ilk vaka aynı tarihte saptanmıştır (T.C Sağlık Bakanlığı, 2020). COVID-19 hastalığına neden olan korona virüs; öksürme, hapşırma, şarkı söyleme, yüksek sesle konuşma gibi aktiviteler sonucu damlacıkların yayılmasıyla veya damlacıkların olduğu bölgeye temas edilmesi ile (ağız, burun veya göz mukozası yoluyla) insandan insana bulaşmaktadır (Kutlu, 2020; Türken ve Köse, 2020). Çok hızlı bulaştığı ve yayıldığı saptanan bu virüs, tüm ülkelerde hükümetlerin benzersiz önlemler, kısitlamalar hatta yasak kararları almalarına neden olmuştur. Türkiye'de virüsün bulaşmasını engellemek, azaltmak ve yavaşlatmak için 12 Mart 2020 tarihinde alınan ilk karar; okulların belirli süre kapatılması, kamu personelinin yurt dışına çımasının koşula bağlanması ve Nisan sonuna kadar spor müsabakalarının seyircisiz oynanmasıdır (T.C Cumhurbaşkanlığı, 2020). Spora yönelik yapılan ikinci açıklama (16 Mart 2020) spor salonlarının, sinema, kafe vb. kapalı alanlar ile birlikte Nisan ayı sonuna kadar kapatılması kararıdır (T.C İçişleri Bakanlığı, 2020). Yaşamın neredeyse tüm alanlarıyla ilgili peş peşe alınan kararlar ile spor alanında nihai olarak 19 Mart 2020 tarihinde voleybol, basketbol ve hentbol liglerinin ertelendiği açıklanmıştır (T.C Gençlik ve Spor Bakanlığı, 2020). Özellikle spor organizasyonlarının; takımdaki oyuncular, antrenörler ve seyirciler ile kalabalık insan toplulukları oluşturması, bunun mesafeyi azaltacağı ve teması arttıracağı, dolayısıyla virüsün yayılmasına neden olacağı bildirilmiştir (Türkmen ve Özsarı, 2020).

Spor sektöründe COVID-19 vakalarının artması ve bilinmez bir dönem yaşanma kaygısıyla birçok spor dalında organizasyonlar, ulusal şampiyonalar ve dünya şampiyonaları iptal edilmiş veya ertelenmiştir. UEFA, tüm Şampiyonlar Ligi maçlarıyla Avrupa Ligleri maçlarını bir sonraki yıla erteleme kararı almıştır. NBA maçları bir süreliğine ertelenmiş, Formula 1 yarışları iptal edilmiştir. Tokyo Olimpiyat Oyunları-2020, 2021 yılına ertelenirken, İngiltere'de Wimbledon Tenis Turnuvası ilk kez iptal edilmiştir. Avrupa Voleybol Konfederasyonu (CEV), 2019/2020 voleybol sezonundaki kulüp, milli takım ve plaj voleybolu organizasyonların 2021 yllına ertelemiş, Türkiye tüm spor 
dallarında liglere bir süreliğine ara vermiştir (IOC, 2020; News, 2020; T.C Cumhurbaşkanlığı, 2020; TVF, 2020b).

Dünyada genelinde pandemi ilanından sonraki 3-4 ay içinde alınan karantina kararları ile insanlara evde kalma çağrısı yapılmıştır. Tüm ülkelerde alınan kararlar, tüm sektörleri etkilemiştir (Hadjidemetriou, Sasidharan, Kouyialis, ve Parlikad, 2020). Pandemi sürecinde uzun süreli evde kalma durumunda olan çoğu kimsenin, belirlenemeyen sürecin verdiği strese maruz kalarak, kayg1, korku ve depresif hissetmesine ve bunların sonucunda uyku bozukluğu veya uyuyamama sorunu yaşamasına neden olmuştur (Altena et al., 2020).

Elit, yarı elit veya rekreasyonel olarak spor yapan sporcuların, pandeminin belirsizliği, liglerin iptali, ekonomik kaygılar, antrenman rutinlerinin değişmesi/azalması gibi nedenlerle hem fiziksel hem de zihinsel olarak etkilendikleri belirlenmiştir (Andreato, Coimbra, ve Andrade, 2020; Håkansson, Moesch, Jönsson, ve Kenttä, 2021; Mehrsafar, Gazerani, Zadeh, ve Sánchez, 2020). Liglere bir süre ara verilmesi ve sonrasında hızlandırılmış bir şekilde tekrar başlatılmasının da sporcular üzerine baskı oluşturduğu, fiziksel ve mental olarak iyileşmelerini yavaşlattı̆ı bildirilmiştir (Håkansson, Jönsson, ve Kenttä, 2020). Aynı zamanda 2019 yılında Uluslararası Olimpiyat Komitesi (IOC)'nin yayınlanan fikir birliği beyanında, elit sporcular arasında akıl sağlığı sorunlarının (anksiyete, depresyon, yeme bozuklukları vb.) yaygın olduğunu ve bu nedenle sporcuların akıl sağlığının ciddiye alınması gerektiğini vurgulamıştır (Reardon et al., 2019). Bu duruma pandeminin getirdiği sosyal, fiziksel ve ruhsal zorluklar eklendiğinde sporcuların dikkatle izlenmesi gerekliliği ortaya çıkmaktadır. Pandemi boyunca tüm bilinmezliğe rağmen sporcular mortalite açısından risk grubu olarak görülmemiştir. Ancak spor performanslarının etkilenebileceği yönünde sürekli kaygilar dile getirilmiştir. Bu durumun, sporcular üzerinde baskıyı artırdığı, yaşam tarzında görülen ciddi değişimlerin, özellikle uyku ve yeme davranışının, sporcuların hem sağlığını hem de performansını etkileyebileceği düşünülebilir. Bu doğrultuda planladığımız bu çalışmada, kısıtlamaların hala devam ettiği dönemde, elit sporcuların stres, uyku, depresyon durumlarını değerlendirmek ve vücut kompozisyonları ile beslenme durumunu belirlemek amaçlanmıştir. 


\section{Yöntem}

Araştırma, İstanbul ilinde TVF'na bağlı 2. Lig Takımı olan Çengelköy Kadın Voleybol takımı sporcuları ile yapılmıştır. Takımda 15 sporcu bulunmaktadır. Bu araştırma, 13 gönüllü sporcu ile 20 Ocak-26 Şubat 2021 tarihleri arasında yürütülmüştür. Araştırma, Sağllk Bilimleri Üniversitesi Bilimsel Araştırmalar Etik Kurulu tarafından 15.01.2021 tarihinde 2/7 sayılı kararı ile onaylanmiştır.

\section{Veri Toplama Araçları}

Veri toplama araçları; araştırıcı tarafından geliştirilen anket formu, duygusal ve davranışsal durumunu değerlendiren ölçekler, 24 saatlik geriye dönük besin tüketim kaydı ve vücut kompozisyon analizinden oluşmaktadır. Tüm veriler sporcular ile yüz yüze görüşme ile elde edilmiştir.

Anket formu: Sporcuların tanımlayıcı özelliklerini, beslenme ve uyku alışkanlıklarını ve takımın karantinada geçirdiği 16-30 Kasım tarihleri arasında döneme ait geriye dönük bazı yaşam tarzı ve beslenme alışkanlıklarındaki değişimi belirlemeye yönelik soruları içermektedir.

Pittsburgh uyku kalitesi indeksi (PUKİ): Bireyin son bir aylık uyku kalitesini değerlendirmek amacıyla geliştirilmiş bir ölçektir. Türkçe geçerlilik güvenirlik çalışması yapılmıştır (Agargun, 1996). Ölçek toplam 24 sorudan oluşmaktadır. Ölçekte 18 soru puanlanarak uyku süresi, öznel uyku kalitesi, alışılmış uyku etkinliği, uyku bozukluğu, uyku ilacı kullanımı, uyku latensi ve gündüz uyku işlev bozukluğu hakkında bilgi vermektedir. Uyku kalitesi değerlendirme puanlarının toplanması ile elde edilmektedir. Elde edilen puanın 5 ve üzerinde olması "kötü" uyku kalitesi olarak sinıflandırılır.

Depresyon, anksiyete ve stres ölçeği kısa formu (DASS-21): Depresyon, anksiyete ve stresin belirtilerini hem klinik örneklemde hem de normal örneklemde ölçmek amacıyla geliştirilmiştir. Türkçe geçerlilik güvenirlik çalışması yapılmıştır (Yılmaz, Hakan ve Arslan, 2017). Ölçek 21 sorudan oluşmaktadır. Her bir faktör için 7 soru bulunmaktadır. 5 'li likert tipi cevap formatına sahip ölçeğin her bir boyuttan alınabilecek en düşük puan 7, en yüksek puan 35'tir. Ölçekte artan puanlar belirtilerin arttı̆̆ına işaret etmektedir. 
Üç faktörlï beslenme anketi (TFEQ18): Yeme davranışının değerlendirildiği bu ölçek 18 sorudan oluşmaktadır. Türkçe geçerlilik güvenirlik çalışması yapılmıştır (Kıraç et al., 2015). Bu ölçek ile bireylerin, yemek yemelerini kısıtlama dereceleri, kontrolsüz olarak yemek yeme seviyeleri ve duygu anlarına göre yemek yeme dereceleri ölçülmektedir. Ölçekte artan puanlar belirtilerin arttığına işaret etmektedir.

24 saatlik geriye dönük besin tüketim kaydı: Bir günlük toplam tüketilen besinleri öğün bazında çeşitlerinin, içeriklerinin, özelliklerinin ve miktarının belirlenmesi amaciyla kullanılan bir kayıt formdur.

Boy ölçer: $1 \mathrm{~mm}$ aralıklı 20-205 cm uzunluğunda Mesitaş ${ }^{\circledR}$ kullanılmıştır.

Vücut kompozisyon analiz ölçümiü: Tanita MC-980MA ${ }^{\circledR}$ ile yapılmıştır.

\section{Veri Toplanması/İşlem Yolu}

Verilerin elde edilmesinde her sporcu ile iki kez yüz yüze görüşülmüştür. İlk görüşmede anket formu, ölçekler ve 24-saatlik geriye dönük besin tüketim kayıtları alınmıştır. İkinci görüşmede vücut analizi için sporculara adet görmedikleri, antrenmanın ve müsabakanın olmadığı günler için randevu verilmiş ve ölçümleri yapılmıştır. Boy uzunluğu ayaklar yan yana ve baş Frankfort düzlemindeyken ölçülmüştür. Vücut analizleri en az 3 saat yiyecek içecek tüketilmediği durumda ve tuvalet sonrası yapılmıştır. Sporcuların boy uzunluğu, vücut ağırlı̆̆ı, BKI değeri, metabolik yaş, toplam yağ kütlesi ve yüzdesi, yağsız ve kas kütlesi, kemik-mineral, protein ve toplam sıvı miktarı ile hücre içi-dışı sıvı miktarı belirlenmiştir. BKI değeri WHO'a göre sınıflandırılmıştır. Ölçeklerden elde edilen veriler, ölçeklerin değerlendirmesi yoluyla puanlandırılmış ve kesme puanlarına göre sınıflandırılmıştır. Bu ölçekler ile sporcuların uyku kaliteleri, depresyon-anksiyete ve stres düzeyleri ile üç faktörlü yeme davranışları (bilişsel kısıtlama, duygusal yeme, kontrolsüz yeme) belirlenmiştir. Üç faktörlü yeme davranış ölçeği skor değerleri standart değerlendirme için kullanılan yüzde (\%) değerine çevrilmiştir (M. Aline, 2004). Besin tüketim kayıtları Bebis programı aracılıyla analiz edilmiş ve sporcuların bir günlük enerji, makro ve mikro besin ögesi alımları hesaplanmıştır. Elde edilen tüm veriler istatistik paket programına kaydedilmiştir. 


\section{Verilerin Analizi}

Verilerin değerlendirilmesinde tanımlayıc istatistikler ortalama, standart sapma, minimum ve maksimum değerler ile sayı ve yüzde dağılımları hesaplanmıştır. Verilerin normallik testi için Shapiro-Wilk kullanılmıştır. Bağımsız iki grup karşılaştırmasında değişkenler normal dağılım gösteriyorsa Student $\mathrm{t}$ testi, normal dağılmıyorsa Mann-Whitney U testi kullanılmıştır. Değişkenler arasındaki ilişkiler değişkenlerin dağılımlarına göre Pearson veya Spearman korelasyon testi kullanılarak incelenmiştir. Besin alımları, BeBIS 8.2 tam versiyon programı ile hesaplanmıştır. İstatistiksel analizler IBM SPSS 22 paket programı ile yapılmıştır ve anlamlılık düzeyi 0.05 kabul edilmiştir.

\section{Bulgular}

Bu çalışmaya katılmaya gönüllü olan 13 elit kadın voleybolcunun çoğu $(\% 76,9)$ genç yetişkin (18-24 yaş)'dir. Sporcuların ortalama voleybol oynama süresinin 11,39 \pm 5,75 y1l olduğu belirlenmiştir. Sporcuların \%30,8'nin COVID-19 hastalı̆̆ına yakalanmıştır (Tablo 1).

Sporcular, sosyal izolasyon / karantina dönüşü ilk maçlarını 12 Ekim 2020 tarihinde yapmışlardır. Lig maçlarının en başında TVF'nin zorunlu olarak yaptırtı̆̆ı COVID-19 testini yaptırdıkları öğrenilmiştir. Bu testte kimse pozitif çıkmamıştır. 15 Kasım 2021 tarihindeki maç öncesi yapılan COVID-19 testi bir sporcuda pozitif çıkmıştır. Sporcu o günkü maça çıkmamış, diğerleri çıkmıştır. Ertesi gün takımdan 3 kişinin, iki gün sonra da 1 kişinin daha pozitif olduğu belirlenmiştir. Takımdan 5 sporcunun COVID-19 hastası olması nedeniyle, takım 2 hafta karantina alınmıştır. COVID-19 hastalığına yakalanan sporcular başka herhangi bir sağlık sorunu yaşamadan iyileşmişlerdir.

Tablo 1. Sporcularn genel özellikleri $(n=13)$

\begin{tabular}{lll}
\hline & $\mathbf{n}$ & $\%$ \\
\hline Cinsiyet & 13 & 100,0 \\
\hline Kadın & & \\
\hline Yaş (yil) & 10 & 76,9 \\
\hline $18-24$ & 2 & 15,4 \\
\hline $25-30$ & 1 & 7,7 \\
\hline$\geq 31$ & & \\
\hline Voleybol oynama süresi (yil) & 8 & 61,5 \\
\hline $5-10$ & 4 & 30,8 \\
\hline $11-20$ & &
\end{tabular}




\begin{tabular}{lll}
\hline$\geq 20$ & 1 & 7,7 \\
\hline Eğitim durumu & 12 & 92,3 \\
\hline Üniversite öğrencisi & 1 & 7,7 \\
\hline Üniversite mezunu & & \\
\hline Medeni durum & 12 & 92,3 \\
\hline Bekar & 1 & 7,7 \\
\hline Evli & & \\
\hline Kronik hastalık tanısı & 1 & 7,7 \\
\hline Var* & 12 & 92,3 \\
\hline Yok & 4 & 30,8 \\
\hline Sigara içme (gün/adet) & 99,2 \\
\hline Evet & 9 & \\
\hline Hayır & & 15,4 \\
\hline Alkollü içecek tüketme & 2 & 84,6 \\
\hline Evet & 11 & \\
\hline Hayır & & 30,8 \\
\hline COVID-19 hastası olma & 4 & 69,2 \\
\hline Evet & 9 & $5 S$ \\
\hline Hayır & Ort & 5,74 \\
\hline & 22,92 & 5,75 \\
\hline Yaş (yıl) & 11,39 & \\
\hline Voleybol oynama süresi (yıl) & 8,00 & \\
\hline Sigara içme (gün/adet) & & \\
\hline${ }^{*}$ Hipotroidi & \\
\hline & & \\
\hline & & \\
\hline
\end{tabular}

Sporcuların vücut kompozisyonlarının ortalama ve alt üst değerleri Tablo 2 'de verilmiştir. Bu çalışmaya katılan kadın voleybol oyuncularının ortalama boy uzunluğu 173,62 \pm 7,69 cm belirlenmiştir. En uzun sporcu $186 \mathrm{~cm}$, en kısa sporcu $160 \mathrm{~cm}$ 'dir. Kadın voleybolcuların vücut yağ yüzdesinin ortalama $\% 22,46 \pm 3,69$, kas kütle ağırlı̆̆ının ortalama $47,50 \pm 4,32 \mathrm{~kg}$ olduğu saptanmıştır. Yağsız kütle ağırlığı en az 44,3 kg iken en fazla 57,7 kg bulunmuştur.

Tablo 2. Sporcularn vïcut kompozisyonu analizi $(n=13)$

\begin{tabular}{lllll}
\hline & Ort. & SS & Min. & Maks. \\
\hline Boy uzunluğu $(\mathrm{cm})$ & 173,62 & 7,69 & 160,0 & 186,0 \\
\hline Vücut ağırlı̆̆1 $(\mathrm{kg})$ & 64,88 & 7,66 & 52,8 & 75,1 \\
\hline BKI $\left(\mathrm{kg} / \mathrm{m}^{2}\right)$ & 21,48 & 1,75 & 18,7 & 24,2 \\
\hline Metabolik yaş (yıl) & 15,85 & 6,31 & 12,0 & 31,0 \\
\hline Yağ kütlesi $(\mathrm{kg})$ & 14,75 & 3,73 & 8,3 & 20,8 \\
\hline Yağ \% & 22,46 & 3,69 & 15,8 & 27,7 \\
\hline Yağsız kütle $(\mathrm{kg})$ & 50,12 & 4,62 & 44,3 & 57,7 \\
\hline Kas kütlesi $(\mathrm{kg})$ & 47,50 & 4,32 & 42,0 & 54,8 \\
\hline Kemik mineral ağırlı̆̆ $(\mathrm{kg})$ & 2,62 & 0,47 & 2,3 & 4,0 \\
\hline Toplam protein miktarı $(\mathrm{kg})$ & 11,40 & 1,30 & 10,0 & 14,0 \\
\hline Toplam sıvı miktarı $(\mathrm{kg})$ & 35,87 & 3,52 & 31,3 & 41,4 \\
\hline Toplam sıvı miktarı $\%$ & 55,13 & 3,80 & 45,2 & 59,3 \\
\hline
\end{tabular}




\begin{tabular}{lllll}
\hline Hücre dışı sıvı miktarı $(\mathrm{kg})$ & 13,90 & 1,58 & 12,1 & 17,8 \\
\hline Hücre içi sıvı miktarı $(\mathrm{kg})$ & 21,97 & 2,41 & 18,8 & 26,2 \\
\hline Hücre dişı sıvı/toplam sıvı oranı & 38,77 & 2,37 & 36,7 & 45,2 \\
\hline
\end{tabular}

Sporcuların ortalama uyku süresinin 7,65 $\pm 1,69$, uyku skorunun $4,92 \pm$ 3,01 ve yarısından fazlasının (\%53,8) kötü uyku kalitesine sahip olduğu bulunmuştur. Sporcuların duygu durumlarına yönelik değerlendirmede $\% 61,5^{\prime}$ inin stres ve anksiyete düzeylerinin normal, \%15,4'ünün depresyon ve anksiyete düzeyinin yüksek olduğu belirlenmiştir. Sporcuların bilişsel kısıtlama, duygusal yeme ve kontrolsüz yeme yüzde puanlarının ortalama değerleri, sirasiyla, $38,88 \pm 24,63 ; 35,46 \pm 28,64$ ve $43,21 \pm 23,85^{\prime}$ tir (Tablo 3).

Ek olarak iyi ve kötü uyku kalitelerine göre uyku skorlarının ortalama değeri sirasiyla 2,67 $\pm 1,03 ; 6,86 \pm 2,80^{\prime}$ dir.

Tablo 3. Sporcuların uyku, stres, anksiyete, depresyon ve yeme davranışlarının değerlendirilmesi $(n=13)$

\begin{tabular}{lll}
\hline & $\mathbf{n}$ & $\%$ \\
\hline Uyku kalitesi & & \\
\hline Iyi & 6 & 46,2 \\
\hline Kötü & 7 & 53,8 \\
\hline Stres & & \\
\hline Normal & 8 & 61,5 \\
\hline Orta & 4 & 30,8 \\
\hline Yüksek & 1 & 7,7 \\
\hline Anksiyete & & \\
\hline Normal & 8 & 61,5 \\
\hline Orta & 3 & 23,1 \\
\hline Yüksek & 2 & 15,4 \\
\hline Depresyon & & \\
\hline Normal & 7 & 53,8 \\
\hline Orta & 4 & 30,8 \\
\hline Yüksek & 2 & 15,4 \\
\hline & Ort & $\mathrm{SS}$ \\
\hline Uyku süresi (saat/gün) & 7,65 & 1,69 \\
\hline Uyku skoru & 4,92 & 3,01 \\
\hline Yeme Davranışı & & 24,63 \\
\hline Bilişsel kisitlama \% & 38,88 & 23,85 \\
\hline Duygusal yeme \% & 35,46 & \\
\hline Kontrolsüz yeme \% & 43,31 & \\
\hline & & \\
\hline
\end{tabular}

Sporcuların uyku kalitelerine göre duygusal durumlarınn, yeme davranışlarının, BKI değerlerinin, vücut bileşenlerinin ve besin ögesi alım ortalamaları ve ortalamaları arasında farkın anlamlılı̆ının belirlenmesi amacıyla 
yapılan test analiz sonuçları Tablo 4' te gösterilmiştir. İyi uyku kalitesine sahip $(n=6)$ ve kötü uyku kalitesi sahip ( $n=7$ ) sporcuların stres, anksiyete, depresyon ve toplam sıvı ağırlıkları arasında anlamlı fark bulunmuştur. Besin tüketimleri göre iyi kalite uykuya sahip olanların günlük ortalama 1283,37 $\pm 268,34$ kkal, kötü uyku kalitesine sahip olanların 1149,43 $\pm 380,63$ kkal enerji aldıkları belirlenmiştir ( $\mathrm{p}<0,05)$. Sporcuların makro besin ögesi bileşenlerine göre ortalama yağ ve karbonhidrat yüzdesi sırasıyla 44,33 $\pm 8,52 ; 36,50 \pm 9,61$ bulunmuştur (Tablo 4).

Ek olarak sporcuların günlük ortalama kalsiyum 512,56 $\pm 248,75$ mg, C vitamini 73,69 $\pm 76,29$ ve protein alım miktarı $52,16 \pm 14,36$ olarak belirlenmiştir. Sporcuların kg başına ortalama protein miktarı 0,81 \pm 0,22 g (Min: 0.36 Max: 1.13). Tüm sporcuların uyku ölçeğinden (PUKİ) elde ettikleri toplam puan ile vücut kompozisyonlanı arasındaki ilişki incelendiğinde yağsız kütle ( $\mathrm{r}=-0,565$ $\mathrm{p}=0,044)$, kas kütlesi $(\mathrm{r}=-0,584 \mathrm{p}=0,036)$ ve protein miktarı $(\mathrm{r}=-0,566 \mathrm{p}=0,044)$ ile negatif yönlü anlamlı ilişki saptanmıştır.

Takımın 16-30 Kasım 2020 tarihinde karantinaya alındı ̆̆ı döneme ait sporcuların bazı yaşam tarzı sorularına yönelik verdikleri cevaplar Tablo 5 'te gösterilmiştir. Sporcuların \%84,6'sının uyku düzeninin değiştiği buna karşılık uyku sürelerinin \%30,8'inde değişmediği görülmüştür. Bu dönemde çoğunluğun (\%46,2) öğün sayısını azalttı̆̆ı ancak iştah ve şekere karşı istek düzeylerini 0 'dan 10'a kadar puanlamaları istendiğinde orta değerden daha yüksek (sirasıyla 6,54 $\pm 2,22 ; 6,77 \pm 2,09$ ) ortalamaya sahip oldukları belirlenmiştir. \%30,8'1 kilo alırken, kimse kilo vermemiştir. Bu dönemde COVID-19 hastalığına neden olan korona virüse karşı besin desteği alanların yüzdesi 61,5'tir.

Tablo 4. Sporcularn uyku kalitelerine göre değişkenlerin değerlendirilmesi (n=13)

\begin{tabular}{|c|c|c|c|c|c|c|}
\hline & \multicolumn{6}{|c|}{ Uyku Kalitesi } \\
\hline & \multicolumn{2}{|l|}{ İyi $(n=6)$} & \multicolumn{2}{|c|}{ Kötü (n=7) } & \multirow{2}{*}{$t / Z$} & \multirow{2}{*}{$p$} \\
\hline & Ort/M* & SS/SO & Ort/M & SS/SO & & \\
\hline Stres skor & 2,33 & 3,20 & 9,00 & 5,51 & 2,602 & 0,025 \\
\hline Anksiyete skor & 0,67 & 0,82 & 6,14 & 4,10 & 3,455 & $0,012^{* *}$ \\
\hline Depresyon skor & 2,50 & 2,74 & 8,71 & 5,85 & 2,377 & $0,037^{* *}$ \\
\hline Bilişsel kısıtlama \% & 43,52 & 29,87 & 34,91 & 20,73 &,- 611 & 0,553 \\
\hline Duygusal yeme \% & 37,03 & 22,93 & 34,11 & 34,60 &,- 176 & 0,864 \\
\hline Kontrolsüz yeme \%† & $6,08^{*}$ & 36,50 & 7,79 & 54,5 &,- 791 & 0,429 \\
\hline BKI $\left(\mathrm{kg} / \mathrm{m}^{2}\right)$ & 22,02 & 1,84 & 21,03 & 1,66 & $-1,017$ & 0,331 \\
\hline Yağ kütlesi (kg) & 16,03 & 4,30 & 13,66 & 3,07 & $-1,161$ & 0,270 \\
\hline Yağsız kütle (kg) & 52,25 & 5,14 & 48,30 & 3,52 & $-1,640$ & 0,129 \\
\hline Toplam siv1 (kg) & 37,87 & 3,84 & 33,87 & 1,72 & $-2,330$ & $0,042 * *$ \\
\hline
\end{tabular}




\begin{tabular}{|c|c|c|c|c|c|c|}
\hline Enerji (kkal) & 1283,37 & 268,34 & 1149,43 & 380,63 &,- 720 & 0,486 \\
\hline Karbonhidrat \% & 36,50 & 9,61 & 46,71 & 8,04 & 2,090 & 0,061 \\
\hline Protein $\%$ & 19,33 & 4,89 & 17,86 & 6,91 &,- 437 & 0,671 \\
\hline Yağ \% & 44,33 & 8,52 & 35,29 & 7,25 & $-2,070$ & 0,063 \\
\hline Lif $(g)$ & 13,30 & 7,94 & 11,63 & 5,97 &,- 432 & 0,674 \\
\hline Kolesterol (mg) & 387,75 & 233,50 & 268,27 & 194,59 & $-1,007$ & 0,335 \\
\hline A vitamini $(\mu \mathrm{g}) \dagger$ & $7,83^{*}$ & 47,00 & 6,29 & 44,00 &,- 714 & 0,475 \\
\hline Tiamin (mg) & 0,66 & 0,19 & 0,51 & 0,23 & $-1,264$ & 0,232 \\
\hline Riboflavin (mg) & 1,16 & 0,28 & 0,89 & 0,27 & $-1,705$ & 0,116 \\
\hline $\mathrm{C}$ vitamini $(\mathrm{g}) \dagger$ & $6,17^{*}$ & 37,00 & 7,71 & 54,00 &,- 714 & 0,475 \\
\hline Kalsiyumt & 8,33 & 50,00 & 5,86 & 41,00 & $-1,143$ & 0,253 \\
\hline B12 vitamini $(\mu \mathrm{g}) \dagger$ & $7,83^{*}$ & 47,00 & 6,29 & 44,00 &,- 714 & 0,475 \\
\hline Demir (mg) & 9,02 & 4,25 & 7,72 & 4,05 &,- 566 & 0,583 \\
\hline Çinko (mg) & 7,56 & 1,44 & 6,07 & 3,00 & $-1,112$ & 0,290 \\
\hline \multicolumn{7}{|c|}{${ }^{*}$ M: Mean Rank; SO: Sum of Rank } \\
\hline \multicolumn{7}{|c|}{${ }^{* *}$ Student $\mathrm{t}$ test $p<0.05 \quad+$ Mann-Whitney $\mathrm{U}$ test } \\
\hline
\end{tabular}

Tablo 5. Sporcuların karantina dönemine ait bazı yaşam tarzı değişiklikleri (n=13)

\begin{tabular}{|c|c|c|}
\hline & $\mathbf{n}$ & $\%$ \\
\hline \multicolumn{3}{|c|}{ Uyku düzeni (gece-gündüz ritmi) } \\
\hline Değişti & 11 & 84,6 \\
\hline Değişmedi & 2 & 15,4 \\
\hline \multicolumn{3}{|l|}{ Uyku süresi } \\
\hline Arttı & 4 & 30,8 \\
\hline Azald 1 & 5 & 38,5 \\
\hline Değişmedi & 4 & 30,8 \\
\hline \multicolumn{3}{|l|}{ Öğüin sayısı } \\
\hline Artt1 & 4 & 30,8 \\
\hline Azald 1 & 6 & 46,2 \\
\hline Değişmedi & 3 & 23,1 \\
\hline \multicolumn{3}{|c|}{ İştah düzeyi (0-10) } \\
\hline Ort. & 6,54 & \\
\hline SS & 2,22 & \\
\hline \multicolumn{3}{|c|}{ Şekere karşı istek düzeyi (0-10) } \\
\hline Ort. & 6,77 & \\
\hline SS & 2,09 & \\
\hline \multicolumn{3}{|c|}{ Kilo değişimi } \\
\hline Artt1 & 4 & 30,8 \\
\hline Değişmedi & 9 & 69,2 \\
\hline \multicolumn{3}{|c|}{ Korona virüse karşı besin desteği alımı } \\
\hline Evet $^{*}$ & 8 & 61,5 \\
\hline Hayır & 5 & 38,5 \\
\hline
\end{tabular}

Karantina döneminde sporcular arasında en fazla oranda artan besinin meyve ve atıştırmalıklar $(\% 61,5)$ olduğu görülmektedir. Ayrıca en fazla 
oranda tüketimi değişmeyen besinlerin ekmek, patates, pilav, makarna $(\% 69,5)$ olduğu belirlenmiştir. Sporculardan \%46,2'sinin sebze yemeyi azalttığı, \%46,2'sinin evde yapılan hamur işi besinleri artırdığı bulunmuştur. Karantina öncesi döneme göre karantinada en çok $(\% 84,6)$ değişmeyen besin peynirdir (Tablo 6).

Tablo 6. Sporcularn karantina dönemine ait besin alımları $(n=13)$

\begin{tabular}{|c|c|c|c|c|c|c|}
\hline & \multicolumn{2}{|c|}{ Artan } & \multicolumn{2}{|c|}{ Azalan } & \multicolumn{2}{|c|}{ Değişmedi } \\
\hline & $\mathbf{n}$ & $\%$ & $\mathbf{n}$ & $\%$ & $\mathrm{n}$ & $\%$ \\
\hline Süt-Yoğurt (süt, yoğurt, kefir) & 4 & 30,8 & 2 & 15,4 & 7 & 53,8 \\
\hline Peynir & 1 & 7,7 & 1 & 7,7 & 11 & 84,6 \\
\hline Et, tavuk, balık & 6 & 46,2 & 1 & 7,7 & 6 & 46,2 \\
\hline Yumurta & 3 & 23,1 & 2 & 15,4 & 8 & 61,5 \\
\hline Ekmek & 1 & 7,7 & 3 & 23,1 & 9 & 69,2 \\
\hline Patates, pilav, makarna & 3 & 23,1 & 1 & 7,7 & 9 & 69,2 \\
\hline Sebze & 7 & 53,8 & 6 & 46,2 & - & - \\
\hline Meyve & 8 & 61,5 & 5 & 38,5 & - & - \\
\hline Yağlı tohumlar (ceviz, badem, findık) & 7 & 53,8 & 6 & 46,2 & - & - \\
\hline Zeytin, sıviyağ & 2 & 15,4 & 3 & 23,1 & 8 & 61,5 \\
\hline Tereyağ, kaymak & 2 & 15,4 & 2 & 15,4 & 9 & 69,2 \\
\hline Evde yapılan hamur işleri (kek-pasta-kurabiye vb.) & 6 & 46,2 & 4 & 30,8 & 3 & 23,1 \\
\hline Atıştırmalık (bisküvi-gofret-çikolata-cips vb.) & 8 & 61,5 & 2 & 15,4 & 3 & 23,1 \\
\hline Alkol & 3 & 23,1 & 3 & 23,1 & 7 & 53,8 \\
\hline
\end{tabular}

\section{Tartışma}

COVID-19 pandemisi devam ederken 2020-2021 sezonunda, İstanbul ili 2. Lig kategorisine toplam 12 voleybol kız takımı katılmış; maçlar iki devreli ve her devre 11 maç, toplamda 22 maç şekilde oynanmıştır (TVF, 2020a). Bu zorlu süreçte takımlardaki bazı sporcularda yeni tip korona virüs pozitif çıkmış, karantinaya alınan takımların maçları ertelenmiştir. Çalışmaya katılan sporcuların \%30,8'i yeni tip korona virüsüne yakalanmış ve tüm takım 2 hafta karantinaya alınmıştır. COVID-19'a yakalanan sporcuların herhangi bir sağlık sorunu yaşamadığı öğrenilmiştir. Şu ana kadar bilinenlere göre sporcuların riskli grup arasında olmadığı bilinmektedir ancak hastalığı geçirdikten sonra komplikasyonların gelişme riski, normal bir bireyinki ile aynı olduğu açılanmıştır (Ibarrola ve Dávolos, 2020). Ayrıca spor performansı ile ilgili ciddi kaygiların olduğunu bildiren çalışmalar mevcuttur (Brito et al., 2021; Paoli ve Musumeci, 2020; Rajpal et al., 2021). Bu kaygıların başında özellikle rekabetçi 
sporcularda ani kalp ölümünün önemli bir nedeni olan miyokardit ile ilgilidir. Yapılan bir çalışmada, COVID-19 enfeksiyonundan kurtulan sporcularda Kardiyak Manyetik Rezonans Görüntüleme (KMR) ile kardiyak anormallikleri değerlendirilmiştir. Futbol, basketbol, hokey gibi sporlarda yarışan asemptomatik veya hafif semptomatik 26 sporcunun (ortalama yaş 19, 15'i erkek) \%46'sının KMR görüntülemesinde geç gadolinyum artışı (nekroz ve fibrozisi yansıtmaktadır) ve \%15'inde miyokarditi düşündüren KMR bulguları görülmüştür (Rajpal et al., 2021). Sporcular için oldukça önemli olan bu konuda henüz literatür oldukça kısıtlıdır.

Covid-19 hastalığına yakalanmanın dışında sporcuların, düzenli olarak antrenmanlarına devam edememesi, gelecek kayg1sı, belirsizlik gibi nedenlerle psikolojik sorunlarında artışlar da gözlemlenmiştir (Mehrsafar et al., 2020). Bu çalışmaya katılan sporcuların; uyku, stres, anksiyete, depresyon ve yeme davranışları değerlendirilmiştir. Sporcuların yarısından fazlasının (\%53,8) kötü uyku kalitesine sahip olduğu bulunmuştur. İyi ve kötü uyku kalitesine sahip sporcuların stres, anksiyete, depresyon ve toplam sıvı ağılıklarında anlamlı bir farka rastlanılmıştır (Tablo 4). Yapılan benzer bir anket çalışmasında, Güney Afrikalı elit ve yarı elit sporcuların pandemi nedeniyle uykularının aşırı derecede değiştiği (\%79; p<0.001), önemli ölçüde karbonhidrat tüketimlerinin arttı̆̆ $(\% 76 ; \mathrm{p}<0.001$; erkekler \%73; kadınlar \%80), sporcuların kendini depresyonda hissettiği (\%52) ve aktif kalmak için motivasyona ihtiyaç duyduğu (\%55) bulunmuştur (Pillay et al., 2020). Sporcuların uyku süresi ve kalitesindeki artış, antrenman/maç performans başarısında artış ile yaralanma/hastalık riskinin azalması arasında anlamlı ilişki belirlenmiştir (Watson, 2017). Bir bireyin en temel biyolojik faaliyetlerinden biri olan uyku, vücut dokularının tüm gün boyunca aktif olan metabolik süreçlerden uzaklaştığı, vücudu fizyolojik performansa hazırladığı, fiziksel gelişim, bilinçli duygusal tepki, bilişsel performans ve yaşam kalitesi için elzem bir bileşendir (AlDabal ve BaHammam, 2011; Watson, 2017). Ayrica sporcuların müsabaka dönemlerinde yaptıkları uzun yolculukların uyku süresi ve kalitesini etkilediği (Fullagar et al., 2015) de bilinmektedir. Ancak bu çalışmada deniz aşırı veya uzun yolculukların uykuya etkisinden bahsetmek uygun değildir. İnsanların hayatlarının 3'te 1'ini uykuda geçirmeleri yaşam için elzemken sporcuların hem sağlık hem de performansı üzerine etkisi büyüktür. Erkek basketbol oyuncuları ile yürütülen bir çalışmada, oyuncuların gece uyku saatleri ortalamasının 5 ile 7 hafta boyunca 6,6 saatten 8,5 saate çıartılıp önceki 
performansları ile karşılaştırıldığında; hızlarında \%5 artış, serbest atış doğruluklarında \%9 artış, serbest atış yüzdesinde ve üçlük atış hedefinde \%9,2'lik bir iyileşme saptanmıştır (Cheri D. Mah, Mah, Kezirian, ve Dement, 2011). Bir başka çalışmada gece uyku süresinin 2 saat arttırılması, tenis oyuncularının servis doğruluğu yüzdesinde \%36'dan \%41'e bir gelişme sağlamıştır (Schwartz ve Simon Jr, 2015). Bu çalışmada kadın voleybol oyuncularının gece-gündüz uyku ritminin \%84,6'sında değiştiği belirlenmiştir. Atletik performans hız, dayanıklılık ve performans doğruluğu dahil olmak üzere bir dizi alanda hafif uyku kaybıyla bile kötüleştiği ve kronik uyku eksikliğinin atletik performansı olumsuz etkilediği belirlenmiştir (Simpson, Gibbs, ve Matheson, 2017). Sporcuların hem performans hem de bağışıklık sistemi üzerindeki etkisi nedeniyle, sporcuların günde en az 7 saat uyumaları ve yatakta cep telefonu ekranına bakmak gibi uyku kalitelerini etkileyen aktivitelerden kaçınmaları önerilmiştir (Huang ve Zhao, 2020).

PUKİ skoru ile stres ve anksiyete düzeyi arasında pozitif yönlü güçlü, yaş ile negatif yönlü zayıf anlamlı bir ilişki saptanmıştır. Pandeminin özellikle genç ve öğrencilerin uyku düzeni etkilediğini bildiren çalışmalar (Hyun, Hahm, Wong, Zhang, ve Liu, 2021; Zhou et al., 2020) gibi bu çalışmadaki sonuçlarda durumu destekler niteliktedir. Ayrıca sporcuların uyku skoru ile antropometrik ölçümleri arasındaki ilişkiyi incelendiğimizde; yağsız vücut kütlesi ( $r=-0,565 \mathrm{p}=0,044)$, vücut kas kütlesi $(\mathrm{r}=-0,584 \mathrm{p}=0,036)$ ve protein mik$\operatorname{tar} 1(\mathrm{r}=-0,566 \mathrm{p}=0,044)$ arasında negatif yönlü anlamlı bir ilişki olduğunu, BKI ile anlamlı bir ilişki olmadığını belirledik. Uyku kalitesinin kötüleşmesi (PUKI skoru artışı), kas kütlesini olumsuz etkilediği sonucuna varılmıştır. Az (saat) uyku veya kötü uyku kalitesi sonucunda insülin benzeri büyüme faktörü-1 (IGF-1) (IGF-1 aracılı sinyal, kas protein sentezinin uyarılmasında merkezi bir unsur) ve testosteron konsantrasyonlarında (protein sentezini uyarır) azalma; katabolik hormon olan glukokortikoid seviyelerinde (kortizol) artışa neden olur. Yüksek kortizol/kortikosteron seviyeleri katabolizma artışına, katabolizma artışı da kas atrofisine ve kas proteinlerinin azalmasına neden olur, bir başka ifadeyle protein yıkımının artışı görülür (Dattilo et al., 2011).

Profesyonel voleybolcuların vücut kompozisyonları değerlendirildiğinde yağ oranının erkeklerde \%7-15, kadınlarda \%10-18 olması ideal olarak kabul edilir (Maughan R. ve L., 2012). Bu çalışmada yağ oranı ortalama 22,46 $\pm 3,69$ (Min-Max: 15,8-27,7) bulunmuştur. Farklı ülkelerde yapılan çalışmalarda Bir- 
leşik Arap Emirlikleri'nde 15-24 yaş arası 10 kadın profesyonel voleybolcunun vücut yağ oranı \%26,6; Çek Cumhuriyeti'nde yaşları 23-32 yıl arasında değişen 18 kadın profesyonel voleybolcunun \%19,8 ve İspanya liginde oynayan 148 elit kadın voleybolcunun yağ oranı ise \%24 olarak bulunmuştur ( Mala et al., 2015; Amita et al., 2017; Martín-Matillas et al., 2014).

İyi bir uyku, dinlenmiş bir vücuda ve bu sayede performans artışına, kasların toparlanmasına yardımcı olurken, uyku kalitesinin ve süresinin azalması, kişide karar verme yeteneğinin ve doğruluğunun azalmasına, çabuk sinirlenmeye, atletik performansın azalmasına, ruh halinde dalgalanmalara, fiziksel ve zihinsel strese neden olur (Cheri D Mah, Kezirian, Marcello, ve Dement, 2018). Çalışmada stres, anksiyete ve depresyon skorlarının yüksek olduğu sporcu oranı \%50'den azdır ancak bu üç değişkenin uyku kalitesi ile hem ilişkili olduğu hem de gruplar arasında anlamlı farklılığın olduğu saptanmıştır. COVID-19 pandemisinin olumsuz etkileri toplumun geneli gibi elit sporcuları da fazlasıyla etkilemiştir. Uzun süre evde kalmanın, sosyal mesafeyi azaltmak amacıyla okulların, toplu kullanım alanlarının kapatılması, spor organizasyonların ertelenmesi veya iptal edilmesi ile insanların sosyal aktivitelerinin azalması, depresyon ve anksiyete gibi psikolojik etkilerin ortaya çıkmasına neden olduğu belirlenmiştir (Huang ve Zhao, 2020). Sporcuların, pandemi sürecinde fiziksel ve zihinsel sağlıkların korumak amacıyla, evde belirli bir kondisyon rutini uygulama (egzersizlerine endurans egzersizler ekleyerek $\mathrm{VO}_{2}$ max'ta önemli düşüşleri engellemek), beslenme biçimine önem verilmesi, zihinsel sağlık için meditasyon, gevşeme teknikleri gibi öneriler verilmiştir (Koçak ve Derya, 2020).

Takım sporcularının antrenman ve maç performansı arttırabilmesi için yeterli ve dengeli bir şekilde beslenmesi gerekmektedir. Yetersiz bir diyet, zayıf kas kütlesi ve kemik mineral yoğunluğu kaybı, aşırı egzersiz ve yaralanma görülme sıklığında artış ile sonuçlanabilmektedir. Karbonhidrat alımı, performansı artırmak ve toparlanma sürecini hızlandırmak için önemlidir. Protein, kas protein sentezi, toparlanma süreci, tokluk sağlar ve vücut kompozisyonunun korunmasına yardımcı olur (Jenner, Buckley, Belski, Devlin, \& Forsyth, 2019). İspanyol Süper Ligi'ndeki 2 takımında oynayan 22 kadın voleybolcunun günlük enerji alımlarının $2835 \pm 178 \mathrm{kkal} /$ gün olduğu saptanmıştır (Mielgo-Ayuso, Zourdos, Calleja-González, Urdampilleta, ve Ostojic, 2015). Bu çalışmada ise $1211,25 \pm 327,53 \mathrm{kkal} /$ gün olduğu, sporcuların karbonhidrat alımlarının düşük, protein alımlarının kabul edilebilir düzeyde yağ 
alımlarının ise yüksek olduğu belirlenmiştir. Ancak protein alımları ile ilgili olarak ağırlık başına ortalama protein miktarının yetersiz olduğu $(0,81 \pm 0,22$ g) görülmektedir. Son yayınlanan sporcu beslenmesi kllavuzu ise günlük protein gereksinmesinin 1,2-1,7 g/kg/gün olduğu bildirilmiştir (Thomas, Erdman, ve Burke, 2016). Elit sporcular ile yapılmış bir başka çalışmada da karbonhidrat alımlarının yetersiz, yağ ve protein alımlarının ise önerilenin üzerinde olduğu sonucuna varılmıştır (Jenner et al., 2019). Dengeli beslenme, bağışıklığın korunması ve geliştirilebilmesi, viral enfeksiyonlardan korunmak için çok önemlidir. Yetersiz beslenme, hastalıklara yakalanmaya açk hale getirir ve iyileşme süresini geciktirir.

Bu çalışmada takımın karantinada kaldığı döneme ait beslenme alışkanlıkları sorgulanmıştır. Sporcuların bu dönemde meyve ve atıştırmalıkları (kek, çikolata, cips vb.) eşit oranda en fazla artırdıkları görülmüştür. Meyve ve sebzeler yüksek miktarda lif, vitamin, mineral ve elektrolit içerirler, yeterli meyve ve sebze alımı, kronik hastalık riskinde azalma ve vücut ağırlığı yönetimi ile ilişkilendirilmiştir (Pem ve Jeewon, 2015). Karantina döneminde özellikle şekerli besinlere düşkünlüğün artı̆̆ı, can sıkıntısıyla yemenin arttığı değişen yaşam tarzının yeme davranışını etkilediği gösterilmiştir (SánchezSánchez et al., 2020; Di Renzo et al., 2020). Meyvenin artırılması sağlıklı bir davranışken aynı oranda atıştırmalıkların artması beslenme durumunu uzun sürede olumsuz etkileyecektir.

Sonuç olarak, profesyonel bir takım ile yürütülen bu çalışmada sporcuların COVID-19 pandemi döneminde yaşam tarzlarının (uyku ve beslenme alışkanlıkları) değiştiği ve stres, anksiyete ve depresif hal varlığı görülmüştür. Zorunlu karantina ve COVID-19 hastalığ 1 korkusu, stres, spor salonlarına ve/veya kulüplerine erişim eksikliği, uyku/uyanma döngüsü değişiklikleri, yeme bozuklukları, gelir kaygısı vb. birçok etken sporcuların performansını, ruh ve fiziksel sağlığını olumsuz etkilenmektedir. Sporcuların bu dönemde yaşadıklarının farkına varmak, performansını ve sağlığını koruyucu geliştirici önlemler almak gereklidir. Ayrıca COVID-19 hastalığına yakalanan sporcuların sağlıkları ve spor performansları izlenmeli, ileri çalışmalar ile değerlendirilmelidir. 


\section{EXTENDED ABSTRACT}

\section{Evaluation of the Sleep Quality and Nutrition Status of Elite Athletes in the COVID-19 Pandemic \\ * \\ Aysun Yüksel \\ Universty of Health Sciences}

Athletes were not considered as a risk group in terms of mortality during the COVID-19 pandemic despite all the unknown. However, constant concerns have been expressed regarding that their sports performance may be affected. It can be thought that this situation increases the pressure on athletes and serious changes in lifestyle, especially sleep and eating behavior, can affect both the health and performance of athletes. In this study, which we planned in this direction, it was aimed to evaluate the stress, sleep, depression status of elite athletes and to determine their body composition and nutritional status in the period when restrictions are still ongoing.

This study was conducted between 20 January and 26 February 2021 with 13 volunteer athletes playing in Çengelköy Women's Volleyball team, a 2nd League Team affiliated to the Turkish Volleyball Federation (TVF) in Istanbul. A questionnaire form was used for the general information and nutritional habits of the athletes, and the PSQI scale was employed to evaluate their sleep quality (Agargun, 1996). Furthermore, the DASS scale which measures the symptoms of depression, anxiety and stress in both a clinical sample and a normal sample, and (Yllmaz, Hakan, \& Arslan, 2017) the TFEQ18 scale were used to evaluate eating behaviors (Kiraç et al., 2015). A 24-hour retrospective food consumption record of all athletes was taken, and finally, body composition analysis (Tanita MC$980 \mathrm{MA}^{\circledR}$ ) of all athletes was performed.

Face-to-face interviews were made with each athlete twice during the data obtaining process. In the first interview, questionnaire form, scales 
and 24-hour retrospective food consumption record were taken. In the second interview, appointments were given to the athletes for body analysis for the days when they did not have menstruation, training and competition, and measurements were made. Height was measured with feet side by side and head in Frankfort plane. Body analyses were performed after at least 3 hours of no food and drink and after toilet. Height, body weight, BMI value, metabolic age, total fat mass and percentage, lean and muscle mass, bone-mineral, protein and total fluid amount and intracellular-extracellular fluid amount of the athletes were determined. BKI value was classified according to WHO. The data obtained from the scales were scored through the evaluation of the scales and classified according to cutoff scores. The sleep quality, depression-anxiety and stress levels of the athletes and three-factor eating behaviors (cognitive restraint, emotional eating, uncontrolled eating) were determined with these scales. The threefactor eating behavior scale score values were converted to the percentage (\%) value used for standard assessment (M. Aline, 2004). Food consumption records were analyzed through the BeBİs 8.2 program and one-day energy, macro and micro nutrient intake of the athletes were calculated. Statistical analyses were made with IBM SPSS 22 package program and the significance level was accepted as 0.05 .

It was determined that the average duration of the athletes playing volleyball was $11.39 \pm 5.75$ years, and $30.8 \%$ of them had COVID-19 disease (Table 1). The athletes played their first match after social isolation/quarantine on 12 October 2020. The athletes caught COVID-19 during the league and were quarantined after the match dated 15 November 2021. All athletes recovered without any other health problems.

The average height of the athletes was detected to be $173.62 \pm 7.69 \mathrm{~cm}$. The tallest athlete is $186 \mathrm{~cm}$ and the shortest is $160 \mathrm{~cm}$. It was determined that the average body fat percentage of female volleyball players was $22.46 \% \pm 3.69$ and the average muscle mass weight was $47.50 \pm 4.32 \mathrm{~kg}$. The lean mass weight was at least $44.3 \mathrm{~kg}$ while it was found to be $57.7 \mathrm{~kg}$ at most.

It was found that the average sleep time of the athletes was $7.65 \pm 1.69$, the sleep score was $4.92 \pm 3.01$, and more than half of them $(53.8 \%$ ) had poor sleep quality. In the evaluation regarding emotional status of athletes, it was identified that $61.5 \%$ of the athletes had normal stress and 
anxiety levels, and $15.4 \%$ had high levels of depression and anxiety. The average values of the cognitive restraint, emotional eating and uncontrolled eating percentage points of the athletes were $38.88 \pm 24.63,35.46 \pm$ 28.64 and $43.21 \pm 23.85$, respectively (Table 3 ). In addition, the average value of sleep scores according to good and bad sleep qualities was $2.67 \pm$ $1.03 ; 6.86 \pm 2.80$, respectively.

A significant difference was found between stress, anxiety, depression and total fluid weights of athletes with good sleep quality $(n=6)$ and poor sleep quality $(n=7)$. According to their food consumption, it was determined that those with good quality sleep received an average of $1283.37 \pm$ $268.34 \mathrm{kcal}$ per day, and those with poor sleep quality received $1149.43 \pm$ $380.63 \mathrm{kcal}$ energy $(\mathrm{p}<0.05)$. The average percentage of fat and carbohydrate based on the macronutrient components of the athletes were $44.33 \pm$ $8.52,36.50 \pm 9.61$, respectively (Table 4). Moreover, the average daily calcium intake of the athletes was $512.56 \pm 248.75 \mathrm{mg}$, vitamin C intake was $73.69 \pm 76.29$ and protein intake was $52.16 \pm 14.36$.

A negatively significant relationship was identified with lean mass ( $\mathrm{r}=$ $-0.565 \mathrm{p}=0.044)$, muscle mass $(\mathrm{r}=-0.584 \mathrm{p}=0.036)$ and protein amount $(\mathrm{r}$ $=-0.566 p=0.044)$ when the relationship between the total score obtained by all athletes from the sleep scale (PSQI) and their body composition was examined. The answers given to some lifestyle questions of the athletes regarding the period when the team was quarantined on 16-30 November 2020 are shown in Table 5. It was observed that the sleep patterns of $84.6 \%$ of the athletes changed, whereas their sleep duration did not change in $30.8 \%$. It was determined that the majority (46.2\%) decreased the number of meals but when they were asked to score their appetite and desire for sugar levels from 0 to 10 , they had a higher average $(6.54 \pm 2.22 ; 6.77 \pm 2.09$, respectively) than the median. $30.8 \%$ gained weight, and nobody lost weight. The percentage of those who received nutritional support during this time against the coronavirus that causes COVID-19 disease is 61.5.

It is seen that the food that increased the most among athletes was fruits and snacks $(61.5 \%)$ during the quarantine period. Furthermore, the foods whose consumption did not change mostly were identified as bread, potato, rice and pasta (69.5\%). It was found that $46.2 \%$ of the athletes decreased the consumption of vegetables, $46.2 \%$ of them increased the pastry 
foods made at home. Compared to the pre-quarantine period, the most unchanged food in quarantine ( $84.6 \%$ ) is cheese (Table 6).

In conclusion, this study conducted with a professional team revealed that the lifestyle of athletes (sleep and eating habits) changed, and the presence of stress, anxiety and depressive state were observed during COVID-19 pandemic. Many factors such as mandatory quarantine and fear of COVID-19 disease, stress, lack of access to gyms and/or sports clubs, changes in sleep/wake cycle, eating disorders, income anxiety, etc. negatively affect the performance, mental and physical health of athletes. It is necessary to be aware of the experiences of athletes during this period and to take measures to protect their performance and health. In addition, the health and sports performance of athletes with COVID-19 disease should be monitored and evaluated with further studies.

\section{Kaynakça / References}

Agargun, M. (1996). Pittsburgh uyku kalitesi indeksinin gecerligi ve guvenirligi. Turk Psikiyatri Dergisi, 7, 107-115.

AlDabal, L., \& BaHammam, A. S. (2011). Metabolic, endocrine, and immune consequences of sleep deprivation. The open respiratory medicine journal, 5, 31 .

Altena, E., Baglioni, C., Espie, C. A., Ellis, J., Gavriloff, D., Holzinger, B., ... Riemann, D. (2020). Dealing with sleep problems during home confinement due to the COVID-19 outbreak: Practical recommendations from a task force of the European CBT-I Academy. Journal of Sleep Research, 29(4), e13052.

Amita, A., Shaimaa, S. A., Mariam, M., Zainab, A., Mona, H., ve Reyad, S. O. (2017). Assessment of Body Composition, Endurance and Nutrient Intakes among Females Team Players in Sports Club. Arab Journal of Nutrition and Exercise (AJNE), 1(3). doi:10.18502/ajne.v1i3.1231

Andreato, L. V., Coimbra, D. R., ve Andrade, A. (2020). Challenges to athletes during the home confinement caused by the COVID-19 pandemic. Strength and Conditioning Journal.

Brito, D., Meester, S., Yanamala, N., Patel, H. B., Balcik, B. J., Casaclang-Verzosa, G., ... Balla, S. (2021). High prevalence of pericardial involvement in college student athletes recovering from COVID-19. JACC: Cardiovascular Imaging, 14(3), 541555 . 
Dattilo, M., Antunes, H. K. M., Medeiros, A., Neto, M. M., Souza, H. S. d., Tufik, S., ve De Mello, M. (2011). Sleep and muscle recovery: endocrinological and molecular basis for a new and promising hypothesis. Medical hypotheses, 77(2), 220222.

Di Renzo, L., Gualtieri, P., Pivari, F., Soldati, L., Attinà, A., Cinelli, G., .. . De Lorenzo, A. (2020). Eating habits and lifestyle changes during COVID-19 lockdown: an Italian survey. Journal of Translational Medicine, 18(1), 229. doi:10.1186/s12967020-02399-5

Fullagar, H. H., Skorski, S., Duffield, R., Hammes, D., Coutts, A. J., ve Meyer, T. (2015). Sleep and athletic performance: the effects of sleep loss on exercise performance, and physiological and cognitive responses to exercise. Sports medicine, 45(2), 161-186.

Hadjidemetriou, G. M., Sasidharan, M., Kouyialis, G., ve Parlikad, A. K. (2020). The impact of government measures and human mobility trend on COVID-19 related deaths in the UK. Transportation research interdisciplinary perspectives, 6, 100167.

Håkansson, A., Jönsson, C., ve Kenttä, G. (2020). Psychological distress and problem gambling in elite athletes during COVID-19 restrictions-A web survey in top leagues of three sports during the pandemic. International journal of environmental research and public health, 17(18), 6693.

Håkansson, A., Moesch, K., Jönsson, C., ve Kenttä, G. (2021). Potentially prolonged psychological distress from postponed olympic and paralympic games during COVID-19-career uncertainty in elite athletes. International journal of environmental research and public health, 18(1), 2.

Huang, Y., ve Zhao, N. (2020). Generalized anxiety disorder, depressive symptoms and sleep quality during COVID-19 outbreak in China: a web-based cross-sectional survey. Psychiatry research, 288, 112954.

Hyun, S., Hahm, H. C., Wong, G. T. F., Zhang, E., ve Liu, C. H. (2021). Psychological correlates of poor sleep quality among US young adults during the COVID-19 pandemic. Sleep medicine, 78, 51-56.

Ibarrola, M., ve Dávolos, I. (2020). Myocarditis in athletes after COVID-19 infection: The heart is not the only place to screen. Sports Medicine and Health Science, 2(3), 172173.

IOC. (2020). Int Statement From The Internatıonal Olympic Committee And The Tokyo 2020 Organising Committee. 24. Mart. https://wwww.olympic.org/news/joint-statementfrom-the-international-olympic-committee-and-the-tokyo-2020-organising-committee. 
Jenner, S. L., Buckley, G. L., Belski, R., Devlin, B. L., ve Forsyth, A. K. (2019). Dietary Intakes of Professional and Semi-Professional Team Sport Athletes Do Not Meet Sport Nutrition Recommendations-A Systematic Literature Review. Nutrients, 11(5), 1160.

Kuraç, D., Kaspar, E. Ç., Avcılar, T., Çakır, Ö. K., Ulucan, K., Kurtel, H., . . Güney, A. İ. (2015). Obeziteyle ilişkili beslenme alışkanlıklarının araştırılmasında yeni bir yöntem "Üç faktörlü beslenme anketi". Clinical and Experimental Health Sciences, 5(3), 162-169.

Koçak, U.Z., ve Derya, Ö. (2020). COVID-19 pandemisi, spor, sporcu üçgeni: Etkilenimler ve öneriler. İzmir Katip Çelebi Üniversitesi Sağlık Bilimleri Fakültesi Dergisi, 5(2), 129-133.

Kutlu, R. (2020). What we have learned about the new coronavirus pandemic, Current Diagnostic and Therapeutic Approaches and The Situation in Turkey. TJFMPC, 14(2), 329-344.

M. Aline, F. L. V.S. S. G. B. d. L. d. v. i. f. R. M. D. V.r. L. L. B. J.-M. K. J. D. r. P. C. (2004). The Three-Factor Eating Questionnaire-R18 is able to distinguish among different eating patterns in a general population. The Journal of nutrition, 134(9), 2372-2380.

Mah, C. D., Kezirian, E. J., Marcello, B. M., ve Dement, W. C. (2018). Poor sleep quality and insufficient sleep of a collegiate student-athlete population. Sleep health, 4(3), 251-257.

Mah, C. D., Mah, K. E., Kezirian, E. J., ve Dement, W. C. (2011). The Effects of Sleep Extension on the Athletic Performance of Collegiate Basketball Players. Sleep, 34(7), 943-950. doi:10.5665/sleep.1132

Mala, L., Maly, T., Zahalka, F., Bunc, V., Kaplan, A., Jebavy, R., ve Tuma, M. (2015). Body composition of elite female players in five different sports games. J Hum Kinet, 45, 207-215. doi:10.1515/hukin-2015-0021

Martín-Matillas, M., Valadés, D., Hernández-Hernández, E., Olea-Serrano, F., Sjöström, M., Delgado-Fernández, M., ve Ortega, F. B. (2014). Anthropometric, body composition and somatotype characteristics of elite female volleyball players from the highest Spanish league. J Sports Sci, 32(2), 137-148. doi:10.1080/02640414.2013.809472

Maughan R., ve L., B. (2012). Nutrition for Athletes, the Nutrition Working Group of the International Olympic Committee. , http://www.audyn.org.uy/sitio/repo/arch/NutritionforAthletes.pdf. 
Mehrsafar, A. H., Gazerani, P., Zadeh, A. M., ve Sánchez, J. C. J. (2020). Addressing potential impact of COVID-19 pandemic on physical and mental health of elite athletes. Brain, behavior, and immunity.

Mielgo-Ayuso, J., Zourdos, M. C., Calleja-González, J., Urdampilleta, A., ve Ostojic, S. M. (2015). Dietary intake habits and controlled training on body composition and strength in elite female volleyball players during the season. Appl Physiol Nutr Metab, 40(8), 827-834. doi:10.1139/apnm-2015-0100

News, B. (2020). Koronavirüs spor dünyasını nasıl etkiledi? 3. Nisan. https://www.bbc.com/turkce/haberler-dunya-52152460.

Paoli, A., ve Musumeci, G. (2020). Elite athletes and COVID-19 lockdown: future health concerns for an entire sector: Multidisciplinary Digital Publishing Institute.

Pem, D., ve Jeewon, R. (2015). Fruit and Vegetable Intake: Benefits and Progress of Nutrition Education Interventions- Narrative Review Article. Iran J Public Health, 44(10), 1309-1321.

Pillay, L., van Rensburg, D. C. C. J., van Rensburg, A. J., Ramagole, D. A., Holtzhausen, L., Dijkstra, H. P., ve Cronje, T. (2020). Nowhere to hide: The significant impact of coronavirus disease 2019 (COVID-19) measures on elite and semi-elite South African athletes. Journal of Science and Medicine in Sport, 23(7), 670-679.

Rajpal, S., Tong, M. S., Borchers, J., Zareba, K. M., Obarski, T. P., Simonetti, O. P., ve Daniels, C. J. (2021). Cardiovascular magnetic resonance findings in competitive athletes recovering from COVID-19 infection. JAMA cardiology, 6(1), 116118.

Reardon, C. L., Hainline, B., Aron, C. M., Baron, D., Baum, A. L., Bindra, A., . . Currie, A. (2019). Mental health in elite athletes: International Olympic Committee consensus statement (2019). British journal of sports medicine, 53(11), 667-699.

Sánchez-Sánchez, E., Ramírez-Vargas, G., Avellaneda-López, Y., Orellana-Pecino, J. I., García-Marín, E., ve Díaz-Jimenez, J. (2020). Eating Habits and Physical Activity of the Spanish Population during the COVID-19 Pandemic Period. Nutrients, 12(9), 2826.

Schwartz, J., ve Simon Jr, R. D. (2015). Sleep extension improves serving accuracy: A study with college varsity tennis players. Physiology $\mathcal{E}$ behavior, 151, 541-544.

Simpson, N., Gibbs, E., ve Matheson, G. (2017). Optimizing sleep to maximize performance: implications and recommendations for elite athletes. Scandinavian journal of medicine $\mathcal{E}$ science in sports, 27(3), 266-274.

T.C. Cumhurbaşkanlığı. (2020). 2020/2 Genelge. Resmi Gazete, 31067. 
T.C İçişleri Bakanlığı. (2020). COVID-19 Pandemi Kararlar https://wwww.icisleri.gov.tr/81-ilvaliligine-koronavirus-tedbirleri-konulu-ek-genelge-gonderildi.

T.C. Sağlık Bakanlığı. (2020). Genel Koronavirüs Tablosu. https://covid19.saglik.gov.tr/TR66935/genel-koronavirus-tablosu.html\#.

T.C. Gençlik ve Spor Bakanlığı. (2020). COVID-19 Pandemi Kararları. https://wwww.aa.com.tr/tr/koronavirus/bakan-kasapoglu-koronavirus-nedeniyle-liglerertelendi/1772105.

Thomas, D. T., Erdman, K. A., ve Burke, L. M. (2016). Position of the Academy of Nutrition and Dietetics, Dietitians of Canada, and the American College of Sports Medicine: Nutrition and Athletic Performance. J Acad Nutr Diet, 116(3), 501528. doi:10.1016/j.jand.2015.12.006

Türken, M., ve Köse, Ş. (2020). Covid-19 bulaş yolları ve önleme. Tepecik Eğitim ve Araştırma Hastanesi Dergisi, 30, 36-42.

Türkmen, M., ve Özsarı, A. (2020). Covid-19 salgını ve spor sektörüne etkileri. International Journal of Sport Culture and Science, 8(2), 55-67.

TVF. (2020a). 2020-2021 Voleybol Sezonu Kadınlar ve Erkekler 2'nci Liglerinin Fikstürleri https://wwww.tvf.org.tr/haberler/2020-2021-voleybol-sezonu-kadinlar-ve-erkekler-2nciliglerinin-fiksturleri-belli-oldu/.

TVF. (2020b). Türkiye Voleybol Federasyonu CEV Organizasyonlan Hakknda Önemli Duyuru. 23. Nisan. https://wwww.tof.org.tr/duyurular/cev-organizasyonlari-hakkinda-onemli-duyuru-2/.

Watson, A. M. (2017). Sleep and athletic performance. Current sports medicine reports, 16(6), 413-418.

WHO. (2020). Coronavirus disease (COVID-19). https://www.who.int/emergencies/diseases/novel-coronavirus-2019.

Yılmaz, Ö., Hakan, B., ve Arslan, A. (2017). Depresyon Anksiyete Stres Ölçeğinin (DASS 21) Türkçe kisa formunun geçerlilik-güvenilirlik çalişmasi. Finans Ekonomi ve Sosyal Araştırmalar Dergisi, 2(2), 78-91.

Zhou, S.-J., Wang, L.-L., Yang, R., Yang, X.-J., Zhang, L.-G., Guo, Z.-C., . . Chen, J.-X. (2020). Sleep problems among Chinese adolescents and young adults during the coronavirus-2019 pandemic. Sleep medicine, 74, 39-47. 


\section{Kaynakça Bilgisi / Citation Information}

Yüksel, A. (2021). COVID-19 pandemi döneminde elit sporcuların uyku kalitesi ile beslenme durumunun değerlendirilmesi OPUS-Uluslararası Toplum Araştırmaları Dergisi, 17(Pandemi Özel Sayısı), 39183942. DOI: $10.26466 /$ opus. 909434 